\title{
Criteria for Adapting Students' Practices to Current Conditions
}

Luciana Truța, Olga Chiș 


\title{
Criteria for Adapting Students' Practices to Current Conditions
}

\author{
Luciana Truța ${ }^{a^{*}}$, Olga Chiș ${ }^{b}$ \\ a Doctoral School "Educational, Reflection, Development", Faculty of Psychology and Educational Sciences, Babeș-Bolyai University Cluj-Napoca, \\ 7 Sindicatelor Street, 400029, Romania \\ ${ }^{b}$ Babes-Bolyai University, Faculty of Psychology and Educational Sciences, 7 Sindicatelor Street, 400029, Cluj-Napoca, Romania \\ *Corresponding author: lucianatruta1@gmail.com
}

Abstract

Keywords:

Online environement; pedagogical practice; adaptation of educational resources; planning activities; curriculum for preschool education.

\section{Zusammenfasung}

\section{Schlüsselworte:}

Online-Umgebung;

pädagogische Praxis; Anpassung

der Bildungsressourcen;

Planungsaktivitäten; Lehrplan

für die Vorschulerziehung.
The present study aims at identifying some efficient ways regarding the development of the pedagogical practice of students in the Pedagogy of Primary and Preschool Education in a synchronous format. Thus, a series of aspects were identified during the first semester that helped us to highlight the strategies that allow students a good knowledge and understanding of the aspects related to pedagogical practice. The study focused on several components viewed and analyzed from two perspectives: of students with studies in the pedagogical field and of those with studies in another field. Thus, the components followed were: ways of conducting meetings in a synchronous format, methods used, the degree of applicability of the contents, the capacity for reflection and self-reflection on the competencies of the teacher, difficulties and suggestions for improvement. The study's conclusions were based both on the students' answers to the applied questionnaire, but also on the analysis performed by the pedagogical practice tutors, resulting in the fact that the strategies used had an impact on all students and that in the future encouraged autonomy in learning.

\section{Introduction}

The current challenges regarding education are also found in the organization and development of the pedagogical practice of students from the specialization of Primary and Preschool Education Pedagogy, through the need to adapt the entire didactic approach to the conditions in the online environment.

In the operational approach to preschool education, change requires the consideration and integration of the following specific issues: variables of change, ongoing stages of change, strategies used to implement change and the effects of this phenomenon.

"In the path of change, each of us builds and/or activates certain barriers. A dedicated teacher is aware of these barriers to overcome them without causing dysfunctions in the teaching and management process or irreconcilable conflicts. Education can no longer be limited to inducing reactive adaptation, effective for students in a given situation, but to achieve effective proactive adaptability necessary for the existence and development of a changing society." (Bocoș, RăduțTaciu \& Chiş, 2015, p. 90).

\section{Theoretical foundation}

Identifying some guidelines for pedagogical orientation in carrying out educational activities in the online environment remains a challenge. We emphasize here the preoccupation of pedagogues to provide answers for the activities to be effective with some questions regarding the actions of orientation, planning, flexibility, adaptation and application of the contents. 
Utilizing the resources of the new pedagogy existing on the university website, we cut a set of reflexive questions meant to guide the teaching activity in terms of adapting to the conditions of activities in the online environment:

- What are the best ways to achieve my goals?

- How could a combination of asynchronous and synchronous activities support student action?

- What are the activities that are difficult to transfer/adapt for online education? Can they be recreated in virtual space without altering their functions?

- Is it possible to achieve the learning objectives that I set for myself only by carrying out synchronous activities?

- How will I stimulate/succeed the involvement of the students in the course in the conditions of a large group of participants if I opt only for synchronous interaction?

- Will be possible for me to fully deliver courses and seminars asynchronously, without real-time video interactions with students? (source: https:/www.ubbcluj.ro/ro/infoubb/noua_pedagogie_u niversitară/).

Starting from these questions, taking into account the knowledge and skills to be trained in the specialization Pedagogy of Primary and Preschool Education (knowledge of the characteristics of different functions and mental processes in the development of childhood; design and implementation of teaching learning, frontal and individualized, which aims the curricular learning itself, adapted both to the context of the class and to another context, different from the class, teaching methodology, teaching strategies, educational contexts for their application, knowledge of the specifics of school learning, to build challenging learning situations for the student and educational contexts to support this process; evaluation of the effectiveness of educational and training programs; use the modern communication development techniques), recreated the strategy of conducting activities with students, trying to maximize time spent online.

Thus, the activities carried out within the pedagogical practice from the first semester of the academic year 2020-2021 took into account practical aspects specific to early education (curriculum content for early education, specific notions, presentation of the terms used, filmed learning activities, their analysis, examples of activities from all experiential fields, exemplification of how to complete activity observation sheets etc.). Collaborative learning by students during synchronous activities were also encouraged.

\section{Research methodology}

The study was conducted between 02.1027.11.2020, the target group being the students from the specialization Pedagogy of Primary and Preschool Education, the first year at the Faculty of Psychology and Educational Sciences, Babeș-Bolyai University of Cluj-Napoca. It provides feedback on the efficiency of the conduct of pedagogical practice, but also a proposal to improve the conduct.

The objectives pursued in the study were:

- Identifying effective ways and methods of organizing pedagogical practice in the online environment;

- Identifying the degree of applicability of the contents conveyed within synchronous meetings specific to the pedagogical practice;

- The capacity of reflection and self-reflection of the students regarding the difficulties encountered within the pedagogical practice was realized in a synchronous format;

- Identifying the degree of knowledge by students of the competencies specific to a teacher;

- The ability of students to self-evaluate their own competencies compared to those specific to a teacher.

The present study included a number of 47 students from the specialization Pedagogy of Primary and Preschool Education. Of these, $18(38,3 \%)$ have previous studies in the pedagogical field and 29 $(61,7 \%)$ have previous studies in another field, as shown in Figure 1. This aspect is important to see the perspectives of the two categories involved in the study, as well as their perception of the pedagogical practice carried out in the online environment. 
Figure 1. The status of students in terms of previous professional training

Specify your status from the point of view of previous professional training

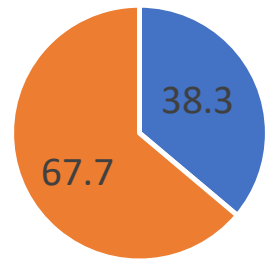

- Studies in pedagogical field (PF)

- Studies in another field (AF)

\section{Results}

Regarding the ways of carrying out the pedagogical practice in the current conditions, we identified the following aspects, highlighted in Figure 2:

Figure 2. Efficient ways of carrying out the pedagogical practice in the current conditions

Wich of the following ways of carrying out the pedagogical practice do you consider effective in the current conditions

38

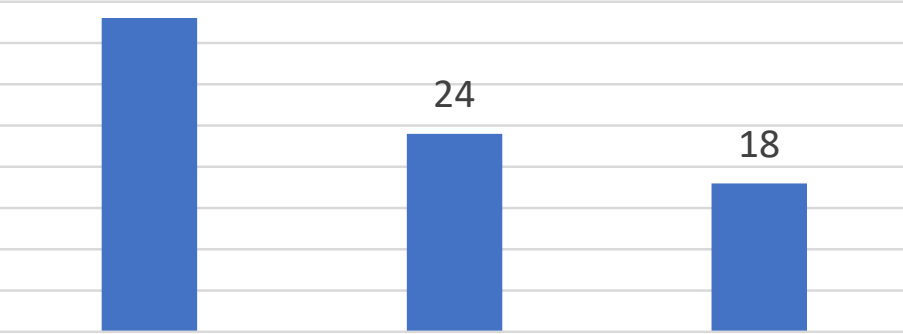

The presentation of

filmed teaching activities and their analysis

$$
\begin{aligned}
& \text { The presentation The presentation of } \\
& \text { theoretical aspects didactic projects and } \\
& \text { specific to the their analysis } \\
& \text { curriculum for early } \\
& \text { education and their } \\
& \text { exemplification }
\end{aligned}
$$

The method most agreed upon by the surveyed students refers to the presentation of filmed teaching activities and their analysis. 38 of the surveyed students chose this method as effective of which 23 were with studies in another field and 15 with studies in the pedagogical field. The next agreed option was to present the theoretical aspects specific to the curriculum for early education and their exemplification (24 students - 19 students with previous studies in another field, 5 students with previous studies in pedagogical field). The presentation of didactic projects and their analysis was the option of 18 students (6 students with previous

studies in another field, 12 students with previous studies in pedagogical field).

Regarding the methods used, the students considered that the discussions based on the topics proposed by the teacher are more effective (33 of the students-19 students with previous studies in another field, 14 students with previous studies in pedagogical field). Discussion based on the topics proposed by students is the second option chosen by them ( 29 of the students-19 students with previous studies in another field, 10 students with previous studies in pedagogical field) and the presentation of some topics made by students is the option of 8 of them (5 students with previous studies in another field, 3 students with previous studies in pedagogical field), according to Figure 3:

Figure 3. Effective methods in carrying out pedagogical practice in synchronous format

Select the methods you consider effective in conducting pedagogical practice in synchronous format (online)

35

30

25

20

15

10

5

0

Discussions based Presentation of Discussion based on topics proposed homework made on topics proposed by students by students 33

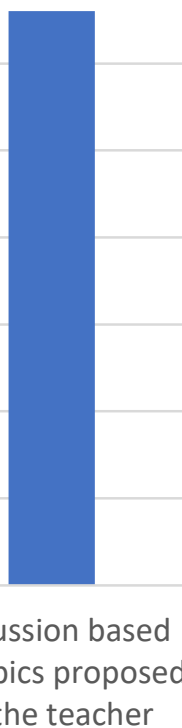


Regarding the degree of applicability of the contents conveyed during the meeting in a synchronous format within pedagogical practice, we found the following:

- Very low: 6\% - 3 students (2 students with previous studies in another field, 1 student with previous studies in pedagogical field)

- Reduced: $20 \%$ - 9 students (6 students with previous studies in another field, 3 students with previous studies in pedagogical field)

- Do not know: 28\% - 13 students (7 students with previous studies in another field, 6 students with previous studies in pedagogical field)

- High: $44 \%$ - 21 students (13 students with previous studies in another field, 8 students with previous studies in pedagogical field)

- Very hight: $2 \%$ - 1 student (1 student with previous studies in pedagogical field)

Figure 4 . The degree of applicability of the contents conveyed within the pedagogical practice

WHAT IS THE DEGREE OF APPLICABILITY OF THE

CONTENTS CONVEYED DURING THE MEETINGS IN SYNCHRONOUS FORMAT WITHIN THE PEDAGOGICAL PRACTICE

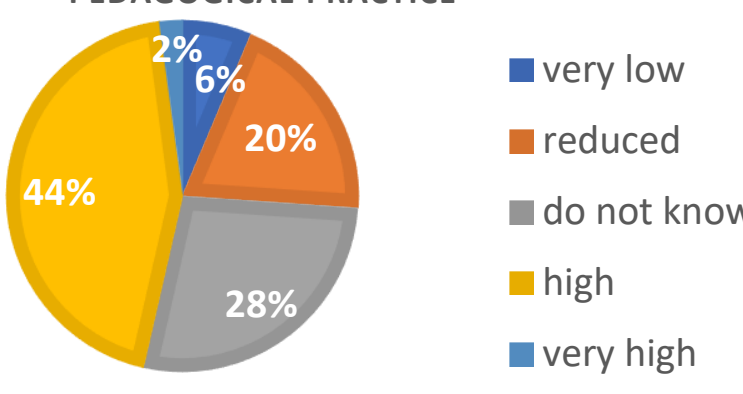

As it appears from the data presented in Figure 4, almost $50 \%$ of the students consider that the degree of applicability of the contents conveyed within the pedagogical practice is high and very high. A worrying aspect refers to the impossibility of almost $30 \%$ of students to decide on how to use/integrate the contents from their personal experience, especially since among them are also students who are based on a training in the pedagogical field. Some correlations will be made later, when the students' perception on their own skills necessary for a teacher approached.

Among the difficulties faced by students, they mentioned issues related to understanding the meaning of specialized terms, time spent on solving tasks, asynchronously, understanding the daily schedule in kindergarten, low concentration in the online environment, how to complete observation sheets (students with previous studies in another field), the impossibility of putting into practice the notions conveyed, direct communication with specialized teachers (students with previous studies in pedagogical field).

Regarding the suggestions about the realization of the pedagogical practice in other ways, students with studies in other fields identified the following: the more in-depth analysis of the curriculum, (4), the realization of some role plays (1), the presentation of several videos with concrete kindergarten activities (2), completing the observation sheets during synchronous meetings (7), 15 of them (52\%) considered that the way to which the pedagogical practice is currently carried out is efficient. Southbased students in the pedagogical field propose the following: more in-depth analysis of the curriculum (3), role-playing games (1), the presentation of several videos with concrete activities in kindergarten (2), the presentation of some activity projects (4), 8 of them (44\%) considering that way to which the pedagogical practice is currently carried out is efficient.

The next aspect addressed in the questionnaire (Figure 5), namely, the identification of the skills needed by the teacher, allows us to identify the degree of knowledge by students of the skills needed by the teacher. Students have developed a hierarchy of these skills as follows:

- Adaptation and use of child-centered teaching and evaluation strategies (methods, teaching aids and form of organization): $89 \%$ - 42 students (27 students with previous studies in another field, 15 students with previous studies in pedagogical field);

- Design and implementation of teachinglearning-assessment activities: 85\% - 40 students (23 students with previous studies in another field, 17 students with previous studies in pedagogical field);

- Documentation, selection, processing. Adaptation of content accessibility: $79 \%$ - 37 students (22 students with previous studies in another field, 15 students with previous studies in pedagogical field);

- Use of effective lifelong learning methods and techniques: $72 \%$ - 34 students (19 students with previous studies in another field, 15 students with previous studies in pedagogical field);

- Self-assessment and continuous improvement 
of professional practices and career development: $70 \%$ - 33 students (19 students with previous studies in another field, 14 students with previous studies in pedagogical field);

- Interpersonal communication in the physical environment: $68 \%$ - 32 students (19 students with previous studies in another field, 13 students with previous studies in pedagogical field);

- Interpersonal communication in the virtual environment: $64 \%$ - 30 students (18 students with previous studies in another field, 12 students with previous studies in pedagogical field);

- Knowledge of the age peculiarities of preschoolers: $60 \%$ - 28 students (13 students with previous studies in another field, 15 students with previous studies in pedagogical field);

- Management of the preschool group: $49 \%-23$ students (10 students with previous studies in another field, 13 students with previous studies in pedagogical field);

- Capitalization in the formal context of acquisitions acquired in nonformal and informal contexts: $45 \%$ - 21 students ( 8 students with previous studies in another field, 13 students with previous studies in pedagogical field);

- Resource management: $40 \%$ - 19 students (8 students with previous studies in another field, 11 students with previous studies in pedagogical field).

Figure 5. Skills needed by a teacher (students' vision)

Identify the competences necessary for a teacher

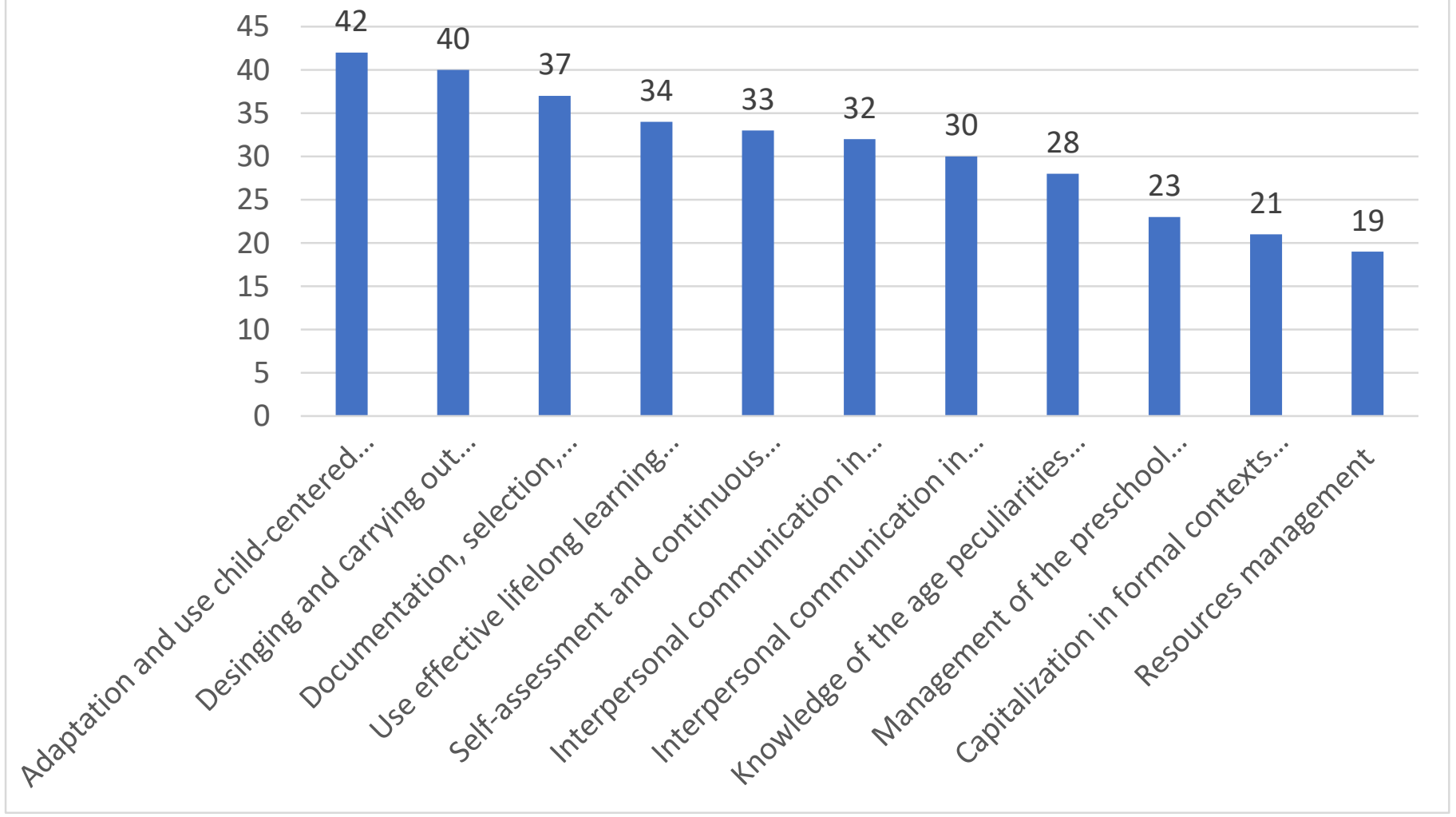

Analyzing the students' answers, we highlight some competencies that students based on pedagogical studies correlate: the adaptation and use of childcentered teaching and assessment strategies (methods, teaching aids and forms of organization) is correlated with the design and implementation of teachinglearning-assessment activities, with knowledge of age peculiarities of preschoolers, with documentation, selection, processing, adapting the accessibility of contents, with the self-evaluation and continuous improvement of the professional practices and with the career evolution (90\% of pedagogical field students). There are also options for using effective lifelong learning methods and techniques and capitalizing in formal contexts on acquisitions acquired in nonformal and informal contexts, which highlights their awareness of lifelong learning that manages "to integrate all three forms of educations: formal, nonformal and informal, allowing the living of real learning experiences in different contexts" (Truța, 2012, p. 7) and the way of organizing and conducting pedagogical practice in the current context allows and 
supports exactly this basic concept of contemporary education.

Analyzing the responses of students based on training in another field, we note that they do not correlate with the skills needed for a teacher, so $93 \%$ of them consider it important to adapt and use childcentered teaching and assessment strategies (methods, means of education and form of organization), but the knowledge of the age peculiarities of preschoolers is considered necessary only by $45 \%$ of them.

Going further and analyzing the answers regarding the necessary competencies of their own educator, students identify the following necessary aspects: adaptation of contents to children, assertive communication, use of diversified strategies, rigorous documentation, applicability of contents, permanent assessment of content comprehension, use of methods effective learning, knowing the needs of children, creating real life situations that allow the application of learned knowledge. These are found in the list of skills of a teacher highlighted by students.

Regarding the self-assessment of the necessary competencies of a teacher for preschool education held by them, we found the following:

Figure 6 . Self-assessment of students on the skills needed by a teacher for preschool education

To what extend do you consider that you have competencies of a teacher for preschool education?

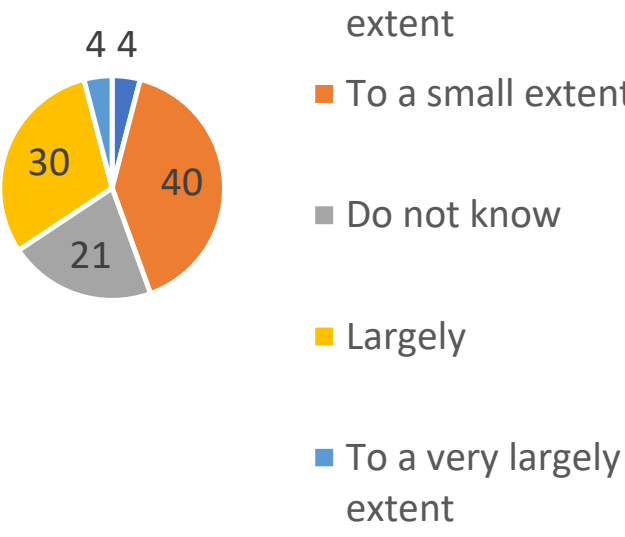

- To a very small extent: $4 \%$ - 2 students with previous studies in another field;

- To a small extent: $40 \%$ - 19 students (9 students with previous studies in another field, 10 students with previous studies in pedagogical field);
- Do not know: 21\% - 10 students (9 students with previous studies in another field, 1 student with previous studies in pedagogical field);

- Largely: 30\% - 14 students (9 students with previous studies in another field, 5 students with previous studies in pedagogical field);

- To a very largely extent; $4 \%$ - 2 students (2 students with previous studies in pedagogical field).

The evaluated aspects regarding the knowledge of the competencies necessary for a teacher, the ability of students to self-evaluate their own competencies compared to those specific to a teacher, highlight a good capacity for self-assessment of their own competencies necessary for a teacher, according to Figure 6. However, correlating the answers offered regarding the degree of applicability of the contents conveyed during the meetings in a synchronous format with those related to the self-assessment of one's own competencies required by a teacher, we find some contradictory answers, both for students in category $\mathrm{AF}$ and to the pedagogical field. Thus, 6 students cannot assess the degree of applicability of the contents, but consider that they have to a large extent the skills necessary for a teacher. Moreover, out of the 10 students cannot assess whether they have the necessary skills for a teacher, 6 of them consider the degree of applicability of the contents high, 1 student considers it low, 2 students very low and 1 student does not know how to appreciate this aspect.

The development of the pedagogical practice led to several finalities found in the student' answers (89\%):

- The stage of activity;

- The usefulness and content of the curriculum;

- What are the areas of development, the types of learning activities and experiential areas;

- The need to correlate activities with real life;

- Completing an activity observation sheet;

- Organization of activities, thematic projects;

- Method means specific to kindergarten activities;

- The need to use language specific to experiential areas centers of interest, difference between children of 0-3 years old and 3-6 years old;

- Communication with parents; 
- Providing feedback to children.

A percentage of $11 \%$ of students (2 students with previous studies in pedagogical field and 3 students with previous studies in another field) consider that they have not learned anything in the pedagogical practice, one of them appreciating that he has to a very large extent the competencies of a teacher, 3 students to a small extent and one of them cannot pronounce. At the same time, for one of them the degree of applicability of the contents is high, another considers it low, another very low and two students cannot pronounce.

Causes specified by the students: studies in another field, non-participation in all meetings within practice. We would like to mention that, as practice tutors, we have drawn a set of causes that generate the appearance of these difficulties we mention here: the lack of individual study to deepen notions, the need to practice, deepen knowledge, contextualizing them in the direction of knowledge transfer and skills.

\section{Conclusions}

In conclusion, $49 \%$ of the surveyed students consider as effective the current way of carrying out the pedagogical practice. However, given that there are requests for the presentation of several videos with concrete activities in kindergarten, we consider that they also appreciate positively the way the pedagogical practice is carried out (9\%) because these aspects have already been found, following with their presentation. It is necessary to resume the presentation of the curriculum for early education, the completion of some activity projects. The students' suggestions are correlated with the difficulties encountered by them, this fact proving a good capacity for self-assessment regarding their own needs.

This analysis highlights the need for introspection by each student on having the necessary skills for a teacher, designing activities in pedagogical practice to identify the specific skills of a teacher, encouraging students to capitalize and develop their own skills.

The answers given by the students show that all contents circulated had an impact on them. For future activities, we aim to use tools of self-assessment, reflective components and highlight the degree of involvement in teaching activities. Clearly, the fundamental steps to operationalize the curricular requirements (curriculum design and development) will be constantly monitored considering that "both processes are mandatory and very present in the daily work of educators" (Tătaru, Glava \& Chiș, 2014, p. 7). At the same time, it is important to keep in mind that "increasing autonomy in learning management has effects on cognitive and motivational processes as well as school performance" (Ceobanu, Cucoș, Istrate \& Pânișoară, 2020, p. 159). The current situation has once again proved the importance of introducing in the school curriculum of several subjects and areas that contribute to self-education (Stănescu, 2017).

We consider that the limits highlighted in the study can be removed by a careful reading of curricular documents, by involving students in task involvement in interactive activities organized synchronously and asynchronously and by identifying new educational resources that can be subject to debate, weekly, in a pedagogical practice class.

"Education can no longer be limited to inducing a reactive adaptation necessary for students in a certain period situation but to achieving an effective proactive adaptability necessary for existence and development in a changing society. Therefore, they become valuable:

- Not only bending to environmental conditions (=adaptation), but especially their anticipation and influence;

- Not only the response to external factors, depending on the individual endowment (=reaction), but also construction, creating conditions for optimal development through a transactional process, proactivism (=proACTION);

- Not only to achieve objectives in terms of cost data (=efficiency), but to fulfilcertain roles and update diverse skills in situations and contexts not only existing or predictable but also possible (=effectiveness).

Specialists in the theory of change consider that the change of knowledge is the easiest to achieve and requires the shortest time. Attitudes and individuals follow." (Bocoș et al. 2015, p. 95).

Authors note: The authors have equal contributions to this article.

Luciana Truta is an associate teacher at the Department of Educational Sciences, Babeș-Bolyai University, Cluj-Napoca. She has a degree in educational science and her fields of interest include: class management, institutional management, efficient methods of institutional communication and 
identifying procedures for streamlining the functionality of the kindergarten.

Olga Chiș is a senior lecturer at the Department of Educational Sciences, Babeș-Bolyai University, ClujNapoca. She graduated Ph.D. in educational sciences and her fields of interest include: parental education, children's literacy, assessment of children in kindergarten and primary school.

\section{References}

Bocoş, M., Răduţ-Taciu, R., \& Chiş, O. (2015), Individual changes and organizational change. Exemplifications for the Romanian preschool teaching system. Procedia Social and Behavioral Sciences, 209 (2015), 90-95.

Bocoş, M. (coord.), Răduţ-Taciu, R., \& Chiş, O. (2015), Tratat de management educațional pentru învățământul primar și preșcolar. Pitești: Paralela 45 Publishing House.
Ceobanu, C., Cucoș, C., Istrate, O., \& Pânişoară, I.-O. (coord.) (2020), Educația digitală, Iași: Polirom Publishing House.

Chiș, O., Jucan D., Catalano, C.V., \& Dragoș, V. (2017), Ghid de practică pedagogică pentru învățământul primar. Pitești: Paralela 45 Publishing House.

Stănescu, M. (2017). Beyond the Given Form. Theatre Pedagogic as Connecting Element Between the Known and the Unknown. Folia linguistica et litteraria, 18, 131-148.

Tătaru, L., Glava, A., \& Chiș, O. (2014), Piramida cunoașterii. Pitești: Diamant Publishing House.

Truța, L., (2012), Instrumente eficiente ale managerului de grădiniță. Cluj-Napoca: Presa Universitară Clujeană Publishing House.

Info UBB. Noua Pedagogie Universitară. Available at: https://www.ubbcluj.ro/ro/infoubb/noua_pedagogie_un iversitara/ (accessed at 25.11.2020) 